\title{
A molecular electron density theory study of the $[3+2]$ cycloaddition reaction of nitrones with ketenes $\uparrow$
}

\author{
Mar Ríos-Gutiérrez, ${ }^{a}$ Andrea Darù, ${ }^{b}$ Tomás Tejero, ${ }^{b}$ Luis R. Domingo*a and \\ Pedro Merino*b
}

The $[3+2]$ cycloaddition (32CA) reaction between nitrones and ketenes has been studied within the Molecular Electron Density Theory (MEDT) at the Density Functional Theory (DFT) MPWB1K/6-311G(d,p) computational level. Analysis of the conceptual DFT reactivity indices allows the explanation of the reactivity, and the chemo- and regioselectivity experimentally observed. The particular mechanism of this 32CA reaction involving low electrophilic ketenes has been elucidated by using a bonding evolution theory (BET) study. It is determined that this reaction takes place in one kinetic step only but in a nonconcerted manner since two stages are clearly identified. Indeed, the formation of the second $\mathrm{C}-\mathrm{O}$ bond begins when the first $\mathrm{O}-\mathrm{C}$ bond is already formed. This study has also been applied to predict the reactivity of nitrones with highly electrophilic ketenes. Interestingly, this study predicts a switch to a two-step mechanism due to the higher polar character of this zw-type 32CA reaction. In both cases, BET supports the non-concerted nature of the 32CA reactions between nitrones and ketenes.

Received 19th December 2016,
Accepted 16th January 2017

DOI: $10.1039 / \mathrm{c} 6 \mathrm{ob02768g}$ rsc.li/obc leading to different heterocyclic compounds depending on the allenic part of the system in which the cycloaddition takes place (Scheme 1).

Despite this synthetic utility, mechanistic studies that allow the interpretation and prediction of the adducts to be obtained with allenes or heteroallenes showing different alternatives like 2-4 are scarce. The reaction of the simplest nitrone $1 a\left(R^{1}, R^{2}=H\right)$ with the simplest allene $2\left(R^{3}, R^{4}=H\right)$ was computationally studied and it was determined that the reaction follows a stepwise mechanism. ${ }^{11}$ Very recently, we

${ }^{a}$ Department of Organic Chemistry, University of Valencia, Dr. Moliner 50, E-46100 Burjassot, Valencia, Spain. E-mail: domingo@utopia.uv.es; http://www. luisrdomingo.com

${ }^{b}$ Laboratorio de Sintesis Asimétrica, Instituto de Síntesis Química y Catálisis Homogénea (ISQCH), Universidad de Zaragoza-CSIC, Zaragoza 50009, Spain. E-mail:pmerino@unizar.es; http://www.pmerino.com

$\dagger$ Electronic supplementary information (ESI) available: BET characterisation of the molecular mechanism of the $z w$-type 32CA reaction between nitrone $\mathbf{1 b}$ and ketene $\mathbf{4 b}$. ELF topological analysis of the stationary points involved in the most favourable reactive channel associated with the 32CA reaction of nitrone $\mathbf{1 b}$ with electrophilic ketene 4c. Tables with the MPWB1K/6-311G(d,p) total and relative electronic energies, in the gas phase and in benzene, and enthalpies, entropies and Gibbs free energies, and the relative ones, computed at room temperature and $1 \mathrm{~atm}$ in benzene, for the stationary points involved in the 32CA reactions between nitrone $\mathbf{1 b}$ and ketenes $\mathbf{4 b , c}$. See DOI: 10.1039/c6ob02768g

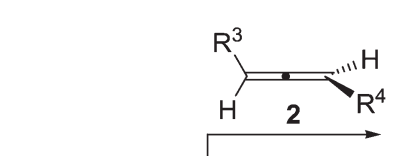<smiles>[R]C=C1C([R])ON([R])C1[R]</smiles><smiles>[R]C=C1ON([R])C([R])C1[R]</smiles>
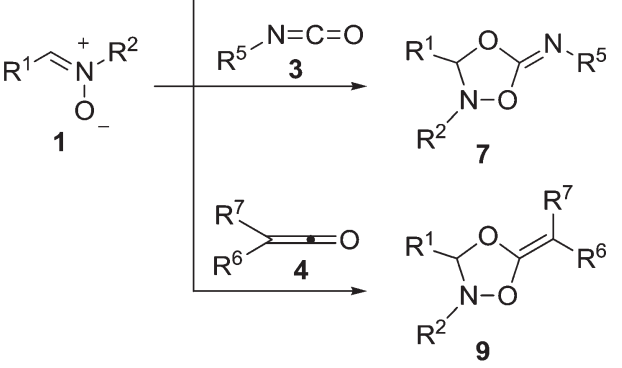<smiles>[R]C1N([R])OC(=O)N1[R]</smiles>

Scheme 1 Reactions of nitrones with allenes and heteroallenes. 
observed the same preference for a stepwise mechanism in the reaction with isocyanates. ${ }^{12}$ Houk and co-coworkers studied the reaction between $\mathrm{N}$-aryl nitrones and alkylarylketenes giving rise to a "pericyclic" cascade with chirality transfer. ${ }^{13}$ However, their study only referred to a particular process in which it was suggested that the first cycloaddition step between the nitrone and the ketene is a one-step reaction but highly asynchronous.

Several Density Functional Theory ${ }^{14}$ (DFT) studies carried out within the Molecular Electron Density Theory (MEDT) ${ }^{15}$ devoted to the study of the reactivity of three-atomcomponents (TACs) participating in 32CA reactions have allowed the establishment of a useful classification of this class of cycloaddition reactions depending on the electronic structure and behaviour of the TAC into pseudodiradical-type (pr-type, typically an azomethineylide 11), ${ }^{16}$ carbenoid-type ( $c b$-type, typically a nitrile ylide 12$)^{17}$ and zwitterionic-type (zw-type, typically a nitrone $\mathbf{1 a})^{16}$ reactions (Scheme 2). The feasibility of the zw-type 32CA reactions depends on the polar character of the reactions, i.e. the nucleophilic character of the nitrones and the electrophilic character of the ethylene derivatives, or vice versa. In general, nitrones are good nucleophiles that react with electron-deficient alkenes. ${ }^{18}$

In order to understand the $z w$-type reactivity ${ }^{16,18}$ of nitrones towards ketenes, the 32CA reaction of nitrone $1 \mathbf{b}\left(\mathrm{R}^{1}, \mathrm{R}^{2}=\mathrm{Me}\right)$ with ketenes $\mathbf{4 b}$ and $\mathbf{4 c}$ yielding cycloadducts (CAs) $\mathbf{9 b , c}$ and $\mathbf{1 0 b}, \mathbf{c}$ are herein studied within the MEDT through DFT calculations at the MPWB1K/6-311G(d,p) computational level (see Scheme 3). The chemoselectivity associated with the 32CA reactions of nitrone $\mathbf{1 b}$ with the $\mathrm{C}=\mathrm{O}$ and $\mathrm{C}=\mathrm{C}$ double bonds of ketenes $\mathbf{4} \mathbf{b}$ and $\mathbf{4 c}$ is first studied. Then, a Bonding Evolution Theory ${ }^{19}$ (BET) analysis of the most favourable chemoisomeric channel associated with the 32CA reaction of nitrone $\mathbf{1 b}$ with ketene $\mathbf{4 b}$ is carried out in order to understand the mechanism of these $z w$-type reactions. Finally, an ELF comparative analysis of the TSs and intermediate related to the most favourable channel associated with the 32CA reaction of nitrone $\mathbf{1 b}$ with ketene $\mathbf{4 c}$ is performed.

\begin{tabular}{ccc}
\hline & TAC & \\
\hline $\begin{array}{c}\text { Azomethine } \\
\text { ylide } \\
\mathbf{1 1}\end{array}$ & Sitrile \\
\hline pseudodiradical & carbenoid & 1a $\left(\mathrm{R}^{1}, \mathrm{R}^{2}=\mathrm{H}\right)$ \\
\hline pr-type & Reactivity \\
\hline
\end{tabular}

Scheme 2 Electronic structure of TACs and the proposed reactivity types in 32CA reactions.

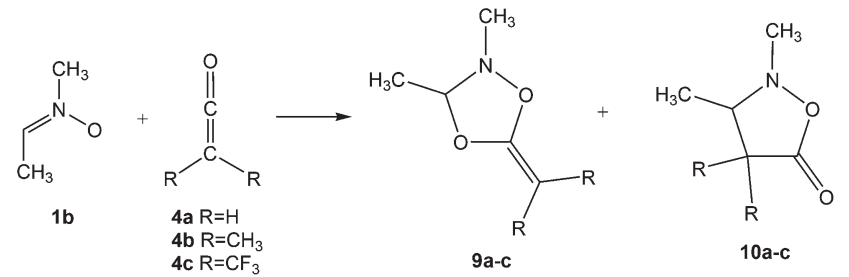

Scheme 3 32CA reactions of nitrone $1 \mathrm{~b}$ with ketenes $4 \mathrm{a}-\mathrm{c}$ yielding cycloadducts $9 a-c$ and $10 a-c$.

\section{Computational methods}

DFT calculations were performed using the MPWB1K functional $^{20}$ together with the $6-311 \mathrm{G}(\mathrm{d}, \mathrm{p})$ basis set. $^{21}$ Optimisations were carried out using the Berny analytical gradient optimization method. ${ }^{22}$ The stationary points were characterised by frequency computations in order to verify that TSs have one and only one imaginary frequency. The IRC paths $^{23}$ were traced in order to check the energy profiles connecting each TS to the two associated minima of the proposed mechanism using the second order González-Schlegel integration method. ${ }^{24}$ The solvent effects of benzene were taken into account by full optimization of the gas phase structures at the MPWB1K/6-311G(d,p) computational level using the polarisable continuum model (PCM) developed by Tomasi's group ${ }^{25}$ in the framework of the self-consistent reaction field (SCRF). ${ }^{26}$ The values of enthalpies, entropies and Gibbs free energies in benzene were calculated with the standard statistical thermodynamics at $25{ }^{\circ} \mathrm{C}$ and $1 \mathrm{~atm} .{ }^{21}$ The electronic structures of the stationary points were characterised by a natural population analysis (NPA), ${ }^{27}$ and by the electron localisation function $(\mathrm{ELF})^{28}$ topological analysis of the electron density. All computations were carried out with the Gaussian 09 suite of programs. ${ }^{29}$ ELF studies were performed with the TopMod ${ }^{30}$ program using the corresponding MPWB1K/6-311G(d,p) monodeterminantal wavefunctions. For the BET study, the corresponding reaction channel was followed by performing the topological analysis of the ELF for 862 nuclear configurations along the IRC path. ELF calculations were computed over a grid spacing of 0.1 a.u. for each structure and ELF basin isosurfaces were obtained for an ELF value of 0.75 a.u.

Conceptual DFT (CDFT) provides different indices to rationalise and understand chemical structure and reactivity. ${ }^{31}$ The global electrophilicity index, ${ }^{32} \omega$, is given by the following expression, $\omega=\left(\mu^{2} / 2 \eta\right)$, in terms of the electronic chemical potential $\mu$ and the chemical hardness $\eta$. Both quantities may be approached in terms of the one-electron energies of the frontier molecular orbitals HOMO and LUMO, $\varepsilon_{\mathrm{H}}$ and $\varepsilon_{\mathrm{L}}$, as $\mu=\left(\varepsilon_{\mathrm{H}}+\varepsilon_{\mathrm{L}}\right) / 2$ and $\eta=\left(\varepsilon_{\mathrm{L}}-\varepsilon_{\mathrm{H}}\right)$, respectively. ${ }^{33}$ The global nucleophilicity index, ${ }^{34} N$, based on the HOMO energies obtained within the Kohn-Sham scheme, ${ }^{35}$ is defined as $N=E_{\text {Hомо }}(\mathrm{Nu})-$ $E_{\text {Hомо }}(\mathrm{TCE})$, where tetracyanoethylene (TCE) is the reference because it presents the lowest HOMO energy in a long series of molecules already investigated in the context of polar organic reactions. The electrophilic $P_{\mathrm{k}}^{+}$and nucleophilic $P_{\mathrm{k}}^{-}$Parr 
functions,${ }^{36}$ which allow for the characterisation of the electrophilic and nucleophilic centers of a molecule, were obtained through the analysis of the Mulliken atomic spin density (ASD) of the radical cation of nitrone $\mathbf{1 b}$ and the radical anion of ketenes $\mathbf{4 a}$ and $\mathbf{4 c}$, by single-point energy calculations from the optimised neutral geometries.

\section{Results and discussion}

The present MEDT study is organised as follows: in section 3.1 , an analysis of the electronic structure of nitrones $\mathbf{1 a}, \mathbf{b}$ is performed in order to understand the $z w$-type reactivity of $\mathbf{1 b}$ in 32CA reactions. Section 3.2 contains an analysis of the CDFT reactivity indices of the reagents involved in the 32CA reactions of nitrone $\mathbf{1} \mathbf{b}$ with ketenes $\mathbf{4 b}$,c. In section 3.3 , the potential energy surfaces (PESs) associated with the chemoisomeric channels associated with the 32CA reactions of nitrone 1b with ketenes $\mathbf{4 b , c}$ are explored and characterised. Section 3.4 discusses a BET study characterising the bonding changes, as well as the energies related to those changes, along the most favourable reaction channel associated with the 32CA reaction of nitrone $\mathbf{1 b}$ with ketene $\mathbf{4 b}$. And finally, in section 3.5, a comparative ELF topological analysis of the TSs and intermediate involved in the most favourable reaction channel associated with the 32CA reaction of nitrone1b with electrophilic ketene $\mathbf{4 c}$ is performed.

\subsection{ELF topological analysis of the electronic structure of nitrones 1a,b}

As commented in the Introduction part, the reactivity of TACs can be correlated with their electronic structure. ${ }^{16,17}$ Thus, an ELF topological analysis of the simplest nitrone 1a and nitrone 1b was first performed in order to characterise the electronic structure of these TACs. The representation and attractor positions of ELF valence basins, as well as ELF electron populations, natural atomic charges and the Lewis structures arising from the ELF topological analysis for nitrones 1a,b are shown in Fig. 1.

The ELF topology of the simplest nitrone 1a permits the establishment of the Lewis structure of this TAC (see Fig. 1). As can be seen, nitrone 1a presents two $\mathrm{V}(\mathrm{O} 1)$ and $\mathrm{V}^{\prime}(\mathrm{O} 1)$ monosynaptic basins, integrating a total of $5.91 e$, and one $\mathrm{V}(\mathrm{O} 1, \mathrm{~N} 2)$ disynaptic basin with a population of $1.39 e$. This behaviour suggests that the $\mathrm{O} 1-\mathrm{N} 2$ bonding region is strongly polarised towards the $\mathrm{O} 1$ oxygen atom. In addition, the presence of one $\mathrm{V}(\mathrm{N} 2, \mathrm{C} 3)$ disynaptic basin integrating $3.89 e$ indicates that the N2-C3 bonding region has a strong double bond character. Consequently, the ELF topology of the simplest nitrone 1a clearly indicates that this TAC is able to participate only in $z w$-type 32CA reactions, as it neither presents a pseudodiradical ${ }^{37}$ nor a carbenoid ${ }^{17}$ electronic structure that would enable it to participate in $p r$ - or $c b$-type 32CA reactions. ${ }^{16,17}$

On the other hand, the ELF topology of nitrone $\mathbf{1 b}$ shows a very similar bonding pattern to that found in the simplest nitrone 1a. Indeed, the substitution of the hydrogen atoms bound to the $\mathrm{N} 2$ nitrogen and $\mathrm{C} 3$ carbon by a methyl group is
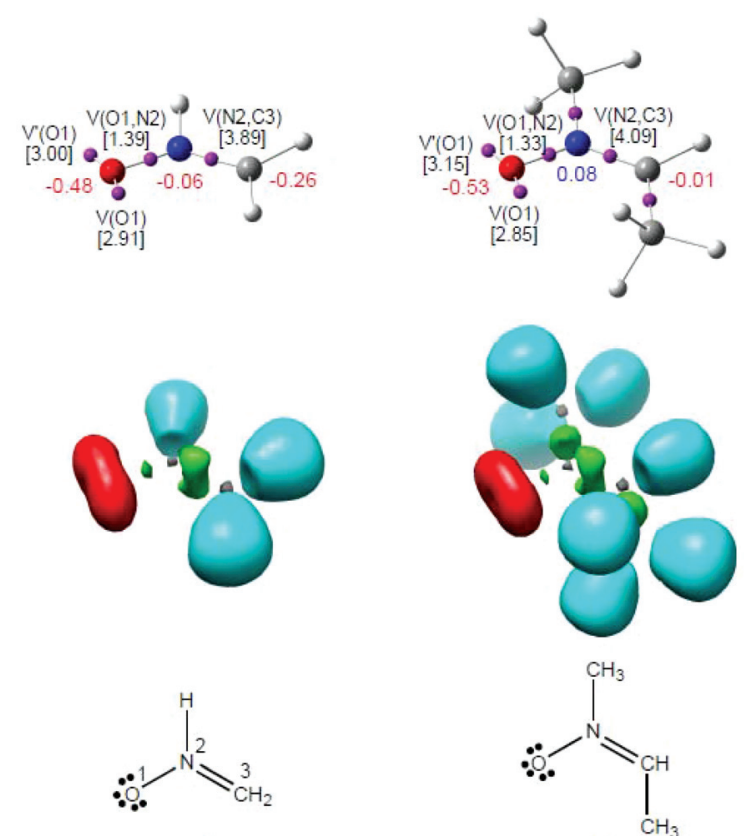

1 a

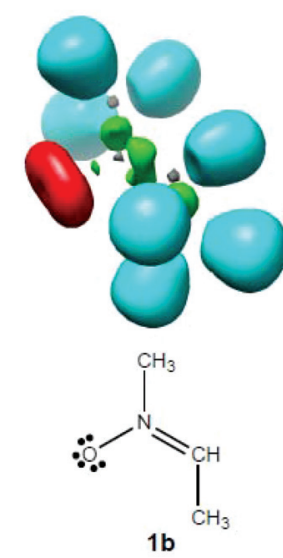

Fig. 1 Representation of ELF attractors and valence basin populations, in $e$, natural atomic charges (negative in red and positive in blue), ELF valence basins and proposed Lewis structures for nitrones 1a,b.

expected to produce no significant electronic changes. The ELF valence basin populations have varied very slightly (see Fig. 1), although in this case the N2-C3 bonding region is characterised by the presence of two disynaptic basins, $\mathrm{V}(\mathrm{N} 2$, $\mathrm{C} 3)$ and $\mathrm{V}^{\prime}(\mathrm{N} 2, \mathrm{C} 3)$, integrating a total population of $4.09 e$. Therefore, according to the ELF topological analysis, nitrone 1b will behave as a zwitterionic TAC participating only in $z w$-type 32CA reactions such as the simplest nitrone $1 \mathbf{a}^{16}$

Although the ELF topological analysis of nitrones $\mathbf{1 a}$ and $\mathbf{1 b}$ allows the establishment of a bonding pattern in these TACs, NPA indicates that neither nitrone has zwitterionic charge distribution. Note that although the $\mathrm{O} 1$ oxygen has a high negative charge, $-0.48 e(\mathbf{1 a})$ and $-0.53 e(\mathbf{1 b})$, the N2 nitrogen presents practically no charge, $-0.06 e(\mathbf{1 a})$ and $0.08 e(\mathbf{1 b})$. Moreover, the C3 carbon appears negatively charged at nitrone 1a, $-0.26 e$, while at nitrone $\mathbf{1 b}$ it presents a null charge, $-0.01 e$.

Thus, although ELF topological analysis provides a bonding pattern concordant with the commonly accepted Lewis structures of nitrones $\mathbf{1 a}, \mathbf{b}$, the NPA is completely in disagreement with the representation of their electronic structure as a 1,2-zwitterionic structure. Nevertheless, ELF topological characterisation of the electron density distribution at these nitrones accounts for their $z w$-type reactivity.

\subsection{Analysis of the CDFT reactivity indices of the reagents} involved in the 32CA reactions of nitrone $1 \mathrm{~b}$ with ketenes $4 \mathrm{~b}, \mathrm{c}$

Studies devoted to polar organic reactions have shown that the analysis of the reactivity indices defined within the $\mathrm{CDFT}^{31 d, 38}$ is a powerful tool to understand the reactivity in polar cycloadditions. Global DFT indices, namely, the electronic chemical 
potential, $\mu$, chemical hardness, $\eta$, electrophilicity, $\omega$, and nucleophilicity, $N$, at the ground state of the reagents involved in these 32CA reactions are given in Table 1.

The electronic chemical potential of nitrone $\mathbf{1 b},-2.95 \mathrm{eV}$, is higher than that of ketenes, $-3.23(\mathbf{4 b})$ and $-5.26(\mathbf{4 c}) \mathrm{eV}$, indicating that along polar reactions the global electron density transfer $(\mathrm{GEDT})^{39}$ will flux from the nitrone framework towards the ketene one.

Along a polar reaction, there is an electron density transfer from the nucleophilic to the electrophilic species, which is measured by the GEDT ${ }^{39}$ value computed at the TS of the reaction; the larger the GEDT at the TS, the more polar the reaction. Note that the GEDT concept comes from the observation that the electron density transfer taking place from the nucleophile to the electrophile along a polar reaction is not a local process, but a global one involving the two interacting frameworks ${ }^{39}$ and depending on the electrophilic/nucleophilic interactions taking place between them.

The electrophilicity $\omega$ and nucleophilicity $N$ indices of the simplest nitrone $1 \mathrm{a}$ are $1.06 \mathrm{eV}$ and $2.92 \mathrm{eV}$, being classified as a moderate electrophile and on the borderline of strong nucleophiles within the electrophilicity ${ }^{40}$ and nucleophilicity ${ }^{41}$ scales. Inclusion of the two electron-releasing (ER) methyl groups at the $\mathrm{N} 2$ and $\mathrm{C} 3$ atoms of the simplest nitrone 1a decreases the electrophilicity $\omega$ index of nitrone $1 \mathrm{~b}$ to $0.80 \mathrm{eV}$ and increases its nucleophilicity $N$ index to $3.46 \mathrm{eV}$. Consequently, nitrone $\mathbf{1 b}$ will behave as a strong nucleophile participating in $z w$-type $32 \mathrm{CA}$ reactions. ${ }^{18}$

On the other hand, the electrophilicity $\omega$ and nucleophilicity $N$ indices of the simplest ketene $\mathbf{4 a}$ are $1.27 \mathrm{eV}$ and 2.58 $\mathrm{eV}$, being classified as a moderate electrophile and nucleophile. Inclusion of the two ER methyl groups at the terminal C6 carbon of ketene 4a decreases the electrophilicity $\omega$ index of ketene $4 \mathbf{b}$ to $1.02 \mathrm{eV}$ and increases its nucleophilicity $N$ index to $2.58 \mathrm{eV}$. Thus, ketene $\mathbf{4 b}$ will behave as a moderate electrophile and a strong nucleophile. Regarding ketene 4c, inclusion of the two electron-withdrawing (EW) trifluoromethyl $\left(\mathrm{CF}_{3}\right)$ groups at the terminal $\mathrm{C6}$ carbon of ketene $4 \mathbf{a}$ notably increases the electrophilicity $\omega$ index to $2.47 \mathrm{eV}$ and decreases the nucleophilicity $N$ index to $1.05 \mathrm{eV}$. Therefore, ketene $\mathbf{4 c}$ will behave as a strong electrophile and a marginal nucleophile. This early analysis of the CDFT global reactivity indices suggests that, as expected, the $z w$-type 32CA reaction of nitrone $\mathbf{1 b}$ with the more electrophilic ketene $\mathbf{4} \mathbf{c}$ will be more favourable than that with ketene $\mathbf{4 b}$.

Table 1 B3LYP/6-31G(d) electronic chemical potential, $\mu$, chemical hardness, $\eta$, electrophilicity, $\omega$, and nucleophilicity, $N$, in eV, of nitrones $1 \mathrm{a}, \mathrm{b}$ and ketenes $4 \mathrm{a}-\mathrm{c}$

\begin{tabular}{lllll}
\hline & $\mu$ & $\eta$ & $\omega$ & $N$ \\
\hline 4c & -5.26 & 5.62 & 2.47 & 1.05 \\
4a & -3.76 & 5.57 & 1.27 & 2.58 \\
1a & -3.43 & 5.55 & 1.06 & 2.92 \\
4b & -3.23 & 5.08 & 1.02 & 3.35 \\
1b & -2.95 & 5.42 & 0.80 & 3.46
\end{tabular}
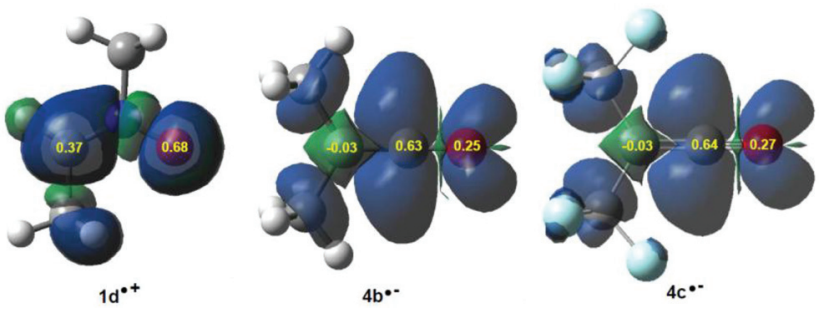

Fig. 2 3D representations of the ASD of the radical cation $1 \mathbf{b}^{\cdot+}$ and the radical anions $4 \mathrm{~b}, \mathrm{c}^{-{ }^{-}}$, together with the nucleophilic $P_{\mathrm{k}}{ }^{-}$Parr functions of nitrone $1 \mathrm{~b}$ and the electrophilic $P_{\mathrm{k}}{ }^{+}$Parr functions of ketenes $4 \mathrm{~b}, \mathrm{c}$.

In polar cycloaddition reactions involving the participation of non-symmetric reagents, the most favourable reactive channel is that involving the initial two-center interaction between the most electrophilic center of the electrophile and the most nucleophilic center of the nucleophile. Recently, Domingo et al. proposed the electrophilic $P_{\mathrm{k}}{ }^{+}$and nucleophilic $P_{\mathrm{k}}{ }^{-}$Parr functions ${ }^{36}$ derived from the changes of spin electron density reached via the GEDT process from the nucleophile to the electrophile as powerful tools in the study of the local reactivity in polar processes. Accordingly, the nucleophilic $P_{\mathrm{k}}{ }^{-}$Parr functions of nitrone $\mathbf{1 b}$ and the electrophilic $P_{\mathrm{k}}{ }^{+}$Parr functions of ketenes $\mathbf{4 b} \mathbf{b}, \mathbf{c}$ were analysed in order to characterise the most electrophilic and nucleophilic centers of the species involved in these 32CA reactions and, thus, to explain the regio- and chemoselectivity experimentally observed (see Fig. 2).

Analysis of the nucleophilic $P_{\mathrm{k}}{ }^{-}$Parr functions of nitrone $1 \mathrm{~b}$ indicates that the $\mathrm{O} 1$ oxygen, ${P_{\mathrm{k}}}^{-}=0.68$, is twice as nucleophilically activated as the C3 carbon, $P_{\mathrm{k}}{ }^{-}=0.37$, while the electrophilic $P_{\mathrm{k}}{ }^{+}$Parr functions of ketenes $\mathbf{4 b}, \mathbf{c}$ indicate that the central C5 carbon is the most electrophilic center of these molecules, $P_{\mathrm{k}}{ }^{+}=0.63(\mathbf{4 b})$ and $0.64(4 \mathbf{c})$. Consequently, the most favourable electrophile-nucleophile interaction along the polar zw-type 32CA reactions of nitrone $\mathbf{1 b}$ with ketenes $\mathbf{4 b}, \mathbf{c}$ will take place between the most nucleophilic center of nitrone $\mathbf{1 b}$, the $\mathrm{O} 1$ oxygen atom, and the most electrophilic center of ketenes $\mathbf{4 b}, \mathbf{c}$, the central C5 carbon, in clear agreement with the regioselectivity experimentally reported first by Taylor ${ }^{42}$ and further by Houk. ${ }^{13}$

On the other hand, analysis of the electrophilic $P_{\mathrm{k}}{ }^{+}$Parr functions of ketenes $\mathbf{4 b}, \mathbf{c}$ also indicates that while the ketene O4 oxygen atom presents some electrophilic activation, $P_{\mathrm{k}}{ }^{+}=$ $0.25(\mathbf{4 b})$ and $0.27(4 \mathbf{c})$, the terminal C6 carbon is slightly electrophilically deactivated, ${P_{\mathrm{k}}}^{+}=-0.03$. This means that along the $z w$-type 32CA reaction of nitrone $\mathbf{1 b}$ with ketenes $\mathbf{4 b}, \mathbf{c}$, the terminal carbon does not participate in the reaction, and thereby, this $z w$-type $32 \mathrm{CA}$ reaction will present a complete $\mathrm{C}=\mathrm{O}$ chemoselectivity.

\subsection{Analysis of the PESs of the 32CA reactions of nitrone $1 \mathrm{~b}$ with ketenes $4 \mathrm{~b}, \mathrm{c}$}

Due to the non-symmetry of both the reagents, the 32CA reactions between nitrone $\mathbf{1 b}$ and ketenes $\mathbf{4 b}, \mathbf{c}$ can take place through four competitive reaction channels, which are related 
to the chemoisomeric attacks of nitrone $\mathbf{1 b}$ on the $\mathrm{C}=\mathrm{O}$ and $\mathrm{C}=\mathrm{C}$ double bonds of ketenes $\mathbf{4 b}, \mathbf{c}$, and with the two regioisomeric approach modes of nitrone $\mathbf{1 b}$ towards each one of the two double bonds of ketenes 4b,c. Due to the high regioselectivity predicted by the analysis of the electrophilic $P_{\mathrm{k}}{ }^{+}$and nucleophilic $P_{\mathrm{k}}{ }^{-}$Parr functions, only the two chemoisomeric channels associated with the initial nucleophilic attack of the nitrone $\mathrm{O} 1$ oxygen on the central C5 carbon of ketenes $\mathbf{4 b , c}$ were studied.

Interestingly, analysis of the PESs associated with the two 32CA reactions indicates that they take place through different mechanisms; the 32CA reaction between nitrone $\mathbf{1 b}$ and ketene $\mathbf{4 b}$ takes place via a one-step mechanism, while that of nitrone 1b with electrophilic ketene 4c takes place via a twostep mechanism (see Scheme 4). Total and relative energies, in the gas phase and benzene, as well as total and relative enthalpies, entropies and Gibbs free energies in benzene, of the stationary points involved in the 32CA reactions between nitrone $\mathbf{1 b}$ and ketenes $\mathbf{4 b , c}$ are given in the ESI. $\dagger$

The activation Gibbs free energy of the 32CA reaction between nitrone $\mathbf{1 b}$ and ketene $\mathbf{4 b}$ presents a low value, $18.8 \mathrm{kcal} \mathrm{mol}^{-1}$, the reaction being exergonic, $-9.7 \mathrm{kcal} \mathrm{mol}^{-1}$ (9b) (see relative Gibbs free energies in Scheme 4). Analysis of the relative Gibbs free energies of TS-CO and TS-CC indicates that this 32CA is kinetically completely chemoselective, as TS-CC is $15.6 \mathrm{kcal} \mathrm{mol}^{-1}$ higher in Gibbs free energy than TS-CO. However, the formation of CA $\mathbf{1 0 b}$ is thermodynamically more favourable than $\mathbf{9 b}$. Consequently, while CA 9b is the product of a kinetic control, CA 10b could become

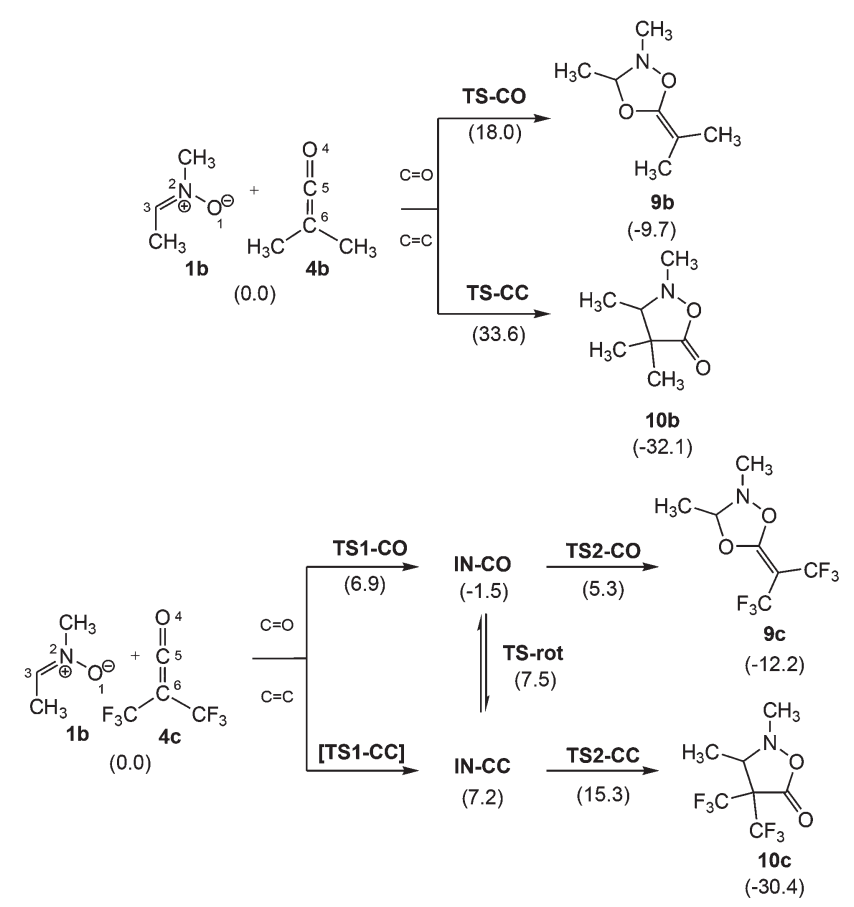

Scheme $4 \mathrm{C}=\mathrm{O}$ and $\mathrm{C}=\mathrm{C}$ chemoisomeric channels associated with the $z w$-type $32 \mathrm{CA}$ reaction between nitrone $1 \mathrm{~b}$ and ketenes $4 \mathbf{b}, \mathbf{c}$. Relative Gibbs free energies, in $\mathrm{kcal} \mathrm{mol}^{-1}$, are given in parentheses. the product of a thermodynamic control under thermal equilibrium conditions.

The PES associated with the 32CA reaction between nitrone $\mathbf{1 b}$ and electrophilic ketene $\mathbf{4 c}$ is more complex. In order to understand the reaction mechanism, the Gibbs free energy profiles of the two competitive channels are depicted in Fig. 3. Analysis of these energy profiles allows one to reach some appealing conclusions: (i) the nucleophilic attack of nitrone $\mathbf{1 b}$ to ketene 4c via TS1-CO has an activation Gibbs free energy of $6.9 \mathrm{kcal} \mathrm{mol}^{-1}$; (ii) the activation Gibbs free energy associated with the ring closure from IN-CO via TS2-CO is $6.8 \mathrm{kcal} \mathrm{mol}^{-1}$, and $8.1 \mathrm{kcal} \mathrm{mol}^{-1}$ from IN-CC via TS2-CC; (iii) this reaction is completely chemoselective, as TS2-CO is $10.5 \mathrm{kcal} \mathrm{mol}^{-1}$ lower in Gibbs free energy than TS2-CC; (iv) formation of CAs 9c and 10c is exergonic by 12.2 and $30.4 \mathrm{kcal} \mathrm{mol}^{-1}$, respectively; (v) interestingly, IN-CO and IN-CC are two conformers being interconvertible by a O1-C5 single bond rotation implying only $0.3 \mathrm{kcal} \mathrm{mol}^{-1}$. Consequently, these intermediates connect both chemoisomeric channels. Thus, under thermodynamic control, CA 9c could be converted into the more thermodynamically stable 10c with an activation energy of 27.5 kcal $\mathrm{mol}^{-1}$; and finally, (vi) a comparison between the energy profiles of the 32CA reactions of nitrone $\mathbf{1 b}$ with ketenes $\mathbf{4 b} \mathbf{b}, \mathbf{c}$ allows one to reach two appealing conclusions: (a) the electrophilic activation of the ketene changes the molecular mechanism and activation energies, but it does not change the thermodynamics of the reaction; and (b) in both reactions, the ring closure is the step controlling the chemoselectivity.

The geometries of the TSs and intermediates involved in the 32CA reactions of nitrone $\mathbf{1 b}$ with ketenes $\mathbf{4 b}, \mathbf{c}$ are given in Fig. 4. At the TSs associated with the 32CA reaction of nitrone 1b with ketene $\mathbf{4 b}$, the distances between the two O1 and C5, and the two $\mathrm{C} 3$ and O4/C6 interacting atoms are: $1.560 \AA$ and $2.219 \AA$ at TS-CO and $1.604 \AA$ and $2.546 \AA$ at TS-CC, respectively. The short distance between the $\mathrm{O} 1$ and $\mathrm{C} 5$ atoms at both

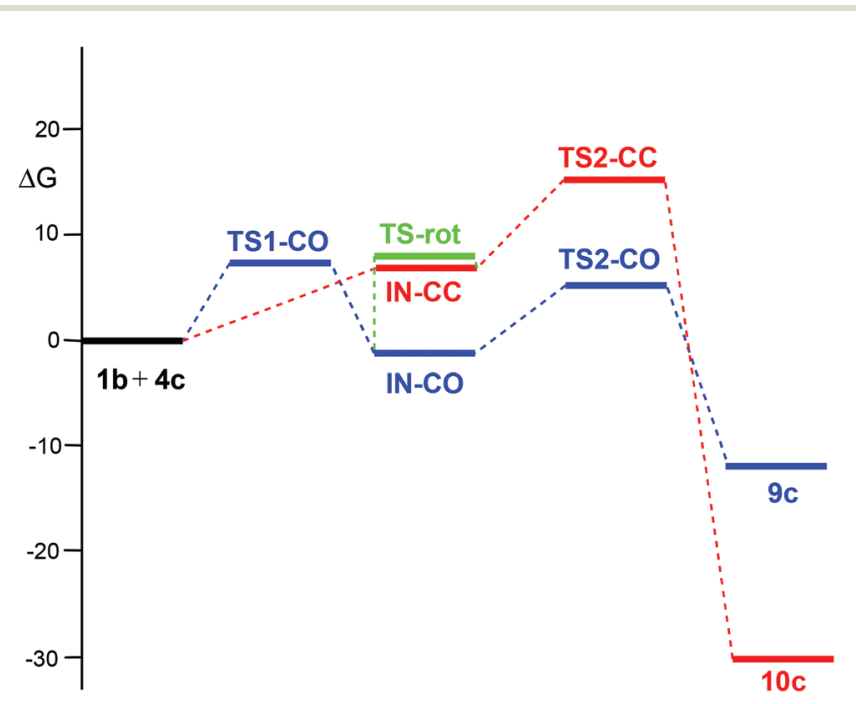

Fig. 3 MPWB1K/6-311G(d,p) Gibbs free energy profile $\left(\Delta G, \mathrm{kcal} \mathrm{mol}^{-1}\right)$, in benzene, of the 32CA reaction between nitrone $1 \mathrm{~b}$ and electrophilic ketene $4 \mathrm{c}$. 


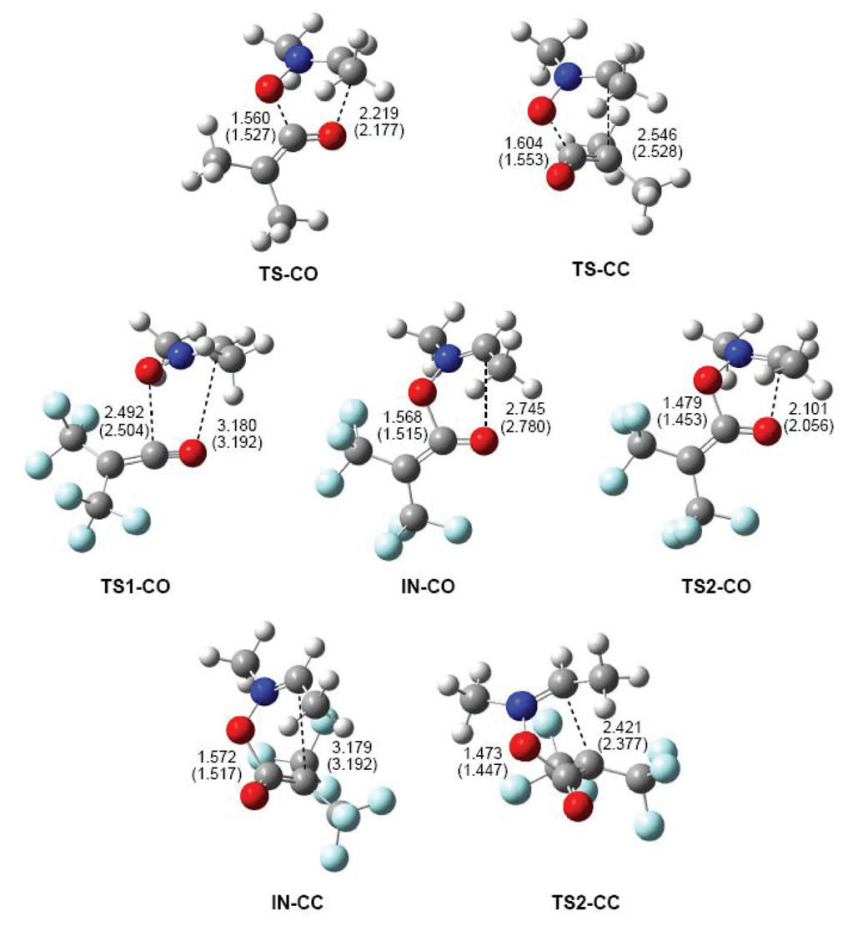

Fig. 4 Geometries of the TSs and intermediates involved in the 32CA reaction of nitrone $1 \mathrm{~b}$ with ketenes $4 \mathrm{~b}, \mathrm{c}$. Lengths are given in Angstroms. Values in parentheses are associated with the lengths in benzene.

TSs indicates that the O1-C5 single bond is already formed. ${ }^{43}$ Consequently, these TSs can be associated with the formation of the second $\mathrm{C} 3-\mathrm{O} 4$ or $\mathrm{C} 3-\mathrm{C} 6$ single bonds.

At TS1-CO, related to the nucleophilic attack of the nitrone O1 oxygen atom on the $\mathrm{C} 5$ carbon of ketene 4c, the distances between the $\mathrm{O} 1$ and $\mathrm{C} 5$, and the $\mathrm{C} 3$ and $\mathrm{O} 4$ atoms are 2.492 and $3.180 \AA$ A. These distances are coherent with an earlytransition state, in clear agreement with its null activation energy. At intermediates IN-CO and IN-CC, the lengths of the O1-C5 single bonds are 1.568 and $1.572 \AA$, respectively, while the distances between the $\mathrm{C} 3$ and $\mathrm{O} 4 / \mathrm{C} 6$ atoms are 2.745 and $3.179 \AA$ A. Finally, at the TSs associated with the ring closure along the two reaction paths, the lengths of the formed O1-C5 single bonds are $1.479 \AA$ (TS2-CO) and 1.473 $\AA$ (TS2-CC), while the distances between the $\mathrm{C} 3$ and $\mathrm{O} 4 / \mathrm{C} 6$ atoms are 2.101 (TS2CO) and 2.421 (TS2-CC) A, respectively.

Inclusion of benzene in the optimisations does not significantly modify the geometries of the TSs (see Fig. 4). The changes in distances in the gas phase and in benzene are found between 0.05 and $0.01 \AA$. In general, the distances between the $\mathrm{O} 1$ and $\mathrm{C} 5$, and the $\mathrm{C} 3$ and $\mathrm{O} 4 / \mathrm{C} 6$ atoms are shorter in benzene as a consequence of the solvent stabilisation of the corresponding species. Only at TS1-CO and intermediates, are the distances between the non-bound atoms slightly increased.

Thorough studies have made it possible to establish good correlations between the polar character of the reactions and their feasibility. ${ }^{44}$ In order to evaluate the electronic nature of the 32CA reaction of nitrone $\mathbf{1 b}$ with ketenes $\mathbf{4 b}, \mathbf{c}$, the GEDT was analysed. The GEDT of a reaction is computed by the sum of the natural atomic charges of the atoms belonging to each framework at the corresponding TSs; the sign indicates the direction of the electron density flux in such a manner that positive values mean a flux from the considered framework to the other one. Reactions with GEDT values near $0.0 e$ correspond to non-polar processes, whereas values higher than $0.2 e$ correspond to polar processes. Thus, at TS-CO and TS-CC associated with the 32CA reaction nitrone $\mathbf{1 b}$ with ketene $\mathbf{4 b}$, the GEDT that takes place from the nitrone to the ketene framework is $0.21 e$ and $0.33 e$, respectively. These values indicate that these TSs have some polar character. At the TSs and intermediates associated with the 32CA reaction nitrone $\mathbf{1 b}$ with electrophilic ketene $\mathbf{4 c}$, the GEDT that takes place from the nitrone to the ketene framework is $0.05 e$ at TS1-CO, 0.45e at IN-CO, $0.44 e$ at IN-CC, $0.41 e$ at TS2-CO and $0.37 e$ at TS2-CC. From these GEDT values some appealing conclusions can be drawn: (i) the negligible GEDT found at TS1-CO is a consequence of the earlier character of this TSs; (ii) a high GEDT is found at the corresponding intermediates, ca.0.45e emphasising the zwitterionic character of these species; (iii) a decrease of the GEDT is found at the TSs associated with the ring closure step as a consequence of a retrodonation process; (iv) the GEDT along the two chemoisomeric channels presents similar values, in spite of the energy differences. This behaviour supports the global character of the electron density transfer from the nucleophilic to the electrophilic framework; and (v) the GEDT at TS2-CO and TS2-CC presents higher values than that at TS-CO and TS-CC as a consequence of the higher electrophilic character of ketene $4 \mathbf{c}, \omega=2.47 \mathrm{eV}$, than ketene 4b, $\omega=1.02 \mathrm{eV}$.

Analysis of the GEDT along the two competitive reaction paths associated with these reactions is in agreement with the low computed activation energies and confirms the $z w$-type character of these 32CA reactions, in which the feasibility of the reaction depends on the electrophilic character of the ketene.

\subsection{BET characterisation of the molecular mechanism of the $z w$-type 32CA reaction between nitrone $1 \mathrm{~b}$ and ketene $4 \mathrm{~b}$}

When trying to achieve a better understanding of bonding changes in organic chemical reactions, the so-called $\mathrm{BET}^{19}$ has proved to be a very useful methodological tool. ${ }^{45}$ BET applies Thom's catastrophe theory (CT) concepts ${ }^{46}$ to the topological analysis of the gradient field of the $\mathrm{ELF}^{28}$ along the reaction coordinate. Several theoretical studies have shown that the topological analysis of the ELF offers a suitable framework for the study of the changes of electron density. This methodological approach is used as a valuable tool to understand the bonding changes along the reaction path and, consequently, to establish the nature of the electronic rearrangement associated with a given molecular mechanism. ${ }^{47}$

Recently, a BET study of the bonding changes along the $z w$ type 32CA reactions of nitrone 1a with ED acrolein 13 was carried out in order to understand the $\mathrm{O}-\mathrm{C}$ and $\mathrm{C}-\mathrm{C}$ bond 
formation processes and to determine the molecular mechanism of these $z w$-type $32 \mathrm{CA}$ processes. ${ }^{43}$ On the other hand, a recent BET study of the molecular mechanism of the ketene-imine Staudinger reaction ${ }^{48}$ permitted one to characterise the participation of the $\mathrm{C}-\mathrm{C}$ double bond of the ketene in the second step of this reaction. Herein, in order to understand the participation of the $\mathrm{O}-\mathrm{C}$ double bond of ketenes, a BET study of the most favourable reaction channel associated with the 32CA reaction between nitrone $\mathbf{1 b}$ and ketene $\mathbf{4 b}$ is performed with the aim of characterising the molecular mechanism of 32CA reactions involving ketenes. The complete BET study is reported in the ESI. $\uparrow$ The equivalence between the topological characterisation of the different phases and the associated chemical process is given in Table 2 .

Some appealing conclusions can be drawn from this BET study: (i) the IRC associated with the 32CA reaction of nitrone 1b with ketene $\mathbf{4 b}$ is divided in eight differentiated phases. A behaviour that clearly indicates that the bonding changes along this one-step mechanism are non-concerted; (ii) formation of the first O1-C5 single bond takes place at a C-O distance of $1.64 \AA$, by the donation of some electron density of the $\mathrm{O} 1$ oxygen lone pairs of the nitrone to the $\mathrm{C} 5$ carbon atom of the ketene moiety. Note that the 01 oxygen is the most nucleophilic center of nitrone $\mathbf{1 b}$ and the C5 carbon corresponds to the most electrophilic center of ketene $\mathbf{4 b}$ (see the chemical process taking place in phase $V$ in Table 2 , and the $\mathrm{V}(\mathrm{O} 1, \mathrm{C} 5)$ disynaptic basin in $\mathbf{P 4}$ in Fig. 5); (iii) formation of this bond demands the asymmetric depopulation of the O4-C5 bonding region of ketene $\mathbf{4 b}$. The large GEDT, 0.34e, taking place along this $z w$-type 32CA reaction favours these bonding changes according to the electronic behaviour anticipated by the Parr functions, which is in agreement with the chemoselectivity experimentally observed; (iv) formation of the second $\mathrm{C} 3-\mathrm{O} 4$ single bond takes place at a $\mathrm{C}-\mathrm{O}$ distance of $1.84 \AA$ by the donation of some of the electron density of the O4 oxygen lone pairs to the C3 pseudoradical center of the nitrone framework (see the chemical process taking place in phase VIII in Table 2, and the $\mathrm{V}(\mathrm{C} 3, \mathrm{O} 4)$ disynaptic basin in P7 in Fig. 5). This carbon participates with a residual electron density of $0.03 e$ in the formation of the $\mathrm{C} 3-\mathrm{O} 4$ single bond; (v) the reaction follows a two-stage one-step mechanism ${ }^{49}$ in which
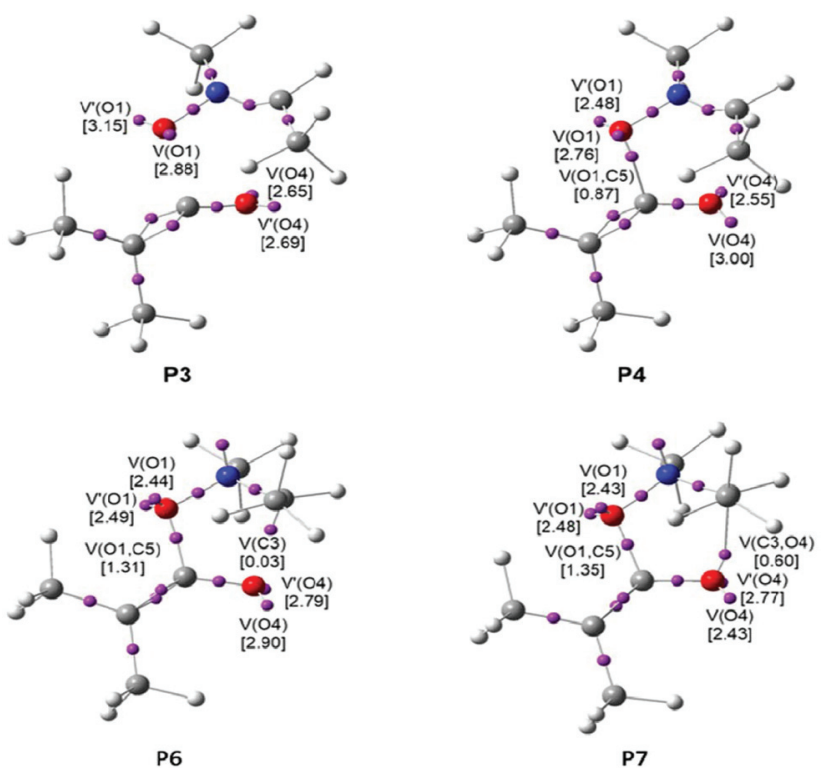

Fig. 5 ELF attractor positions for the points of the IRC defining phases IV, V, VII and VIII involved in the formation of the O1-C5 and C3-O4 single bonds along the most favourable reactive channel associated with the $z w$-type 32CA reaction between nitrone $1 \mathrm{~b}$ and ketene $4 \mathrm{~b}$. The electron populations, in e, are given in brackets.

the formation of the second $\mathrm{C} 3-\mathrm{O} 4$ one begins when the first O1-C5 single bond is practically already formed. This fact also emphasises that the bonding changes in this one-step reaction are non-concerted processes; (vi) the activation energy associated with this 32CA reaction, $9.3 \mathrm{kcal} \mathrm{mol}^{-1}$, can be mainly associated with the depopulation of the O4-C5 and N2-C3 bonding regions towards the $\mathrm{O} 4$ oxygen and the $\mathrm{N} 2$ nitrogen, respectively, which is demanded before the donation of the electron density of the O4 oxygen to the C3 carbon; (vii) the present BET study allows the establishment of the molecular mechanism of the zw-type 32CA reactions between nitrones and ketenes as a $[2 n, 2 n]$ mechanism, ${ }^{50}$ i.e. only two nonbonding electrons of the oxygen lone pairs of nitrone $\mathbf{1 b}$ and two non-bonding electrons of the oxygen lone pairs of ketene 4b are mainly involved in the formation of the two $\mathrm{C}-\mathrm{O}$ single bonds in CA $9 \mathbf{b}$.

Table 2 Sequential bonding changes along the $z w$-type 32CA reaction between nitrone $1 \mathrm{~b}$ and ketene $4 \mathrm{~b}$, showing the equivalence between the topological characterisation of the different phases and the associated chemical process

\begin{tabular}{|c|c|c|c|c|c|c|c|}
\hline & Phases & $d(\mathrm{O} 1-\mathrm{C} 5)$ & $d(\mathrm{C} 3-\mathrm{O} 4)$ & $\Delta E$ & GEDT & Topological characterisation & Chemical process \\
\hline $\mathrm{a}$ & $I-I V$ & $3.04 \geq d>1.79$ & $3.26 \geq d>2.39$ & 8.6 & $\leq 0.34$ & $\begin{array}{l}\text { Depopulation of the } \mathrm{V}(\mathrm{O} 4, \mathrm{C} 5) \\
\text { disynaptic basin }\end{array}$ & $\begin{array}{l}\text { Depopulation of the } \mathrm{O} 4-\mathrm{C} 5 \\
\text { bonding region }\end{array}$ \\
\hline $\mathrm{b}$ & $V$ & $1.64 \geq d>1.61$ & $2.39 \geq d>2.33$ & $9.0(0.4)$ & 0.34 & $\begin{array}{l}\text { Formation of the } \mathrm{V}(\mathrm{O} 1-\mathrm{C} 5) \\
\text { disynaptic basin }\end{array}$ & $\begin{array}{l}\text { Formation of the O1-C5 single } \\
\text { bond }\end{array}$ \\
\hline $\mathrm{c}$ & $V I$ & $1.61 \geq d>1.46$ & $2.33 \geq d>1.91$ & $4.5(-4.5)$ & $\leq 0.34$ & $\begin{array}{l}\text { Depopulation of the } \mathrm{V}(\mathrm{N} 2, \mathrm{C} 3) \\
\text { disynaptic basin and the formation } \\
\text { of the } \mathrm{V}(\mathrm{N} 2) \text { monosynaptic basin }\end{array}$ & $\begin{array}{l}\text { Rupture of the N2-C3 double } \\
\text { bond and the formation of the } \\
\text { N2 nitrogen lone pair }\end{array}$ \\
\hline $\mathrm{d}$ & $V I I$ & $1.46 \geq d>1.44$ & $1.91 \geq d>1.84$ & $1.7(-3.1)$ & $\leq 0.24$ & $\begin{array}{l}\text { Formation of the non-bonding } \\
\mathrm{V}(\mathrm{C} 3) \text { monosynaptic basin }\end{array}$ & $\begin{array}{l}\text { Formation of the } \\
\text { C3 pseudoradical center }\end{array}$ \\
\hline $\mathrm{e}$ & $V I I I$ & $1.44 \geq d \geq 1.37$ & $1.84 \geq d \geq 1.42$ & $-22.7(-24.1)$ & $\leq 0.21$ & $\begin{array}{l}\text { Formation of the } \mathrm{V}(\mathrm{C} 3-\mathrm{O} 4) \\
\text { disynaptic basin }\end{array}$ & $\begin{array}{l}\text { Formation of the } \mathrm{C} 3-\mathrm{O} 4 \text { single } \\
\text { bond }\end{array}$ \\
\hline
\end{tabular}


3.5. ELF topological analysis of the stationary points involved in the most favourable reactive channel associated with the 32CA reaction of nitrone $1 \mathrm{~b}$ with electrophilic ketene $4 \mathrm{c}$

In order to understand how the EW substitution in the ketene can modify the molecular mechanism of the $z w$-type 32CA reaction of nitrones with electrophilic ketenes, the bonding patterns of the stationary points involved in the most favourable reactive channel associated with the 32CA reaction of nitrone 1b with electrophilic ketene $\mathbf{4 c}$ were characterised by ELF topological analysis. ELF topological analysis is reported in the ESI. $\dagger$

Some appealing conclusions can be obtained from this ELF topological analysis: (i) at TS1-CO, no bonding change with respect to MC-c is observed. The bonding pattern of TS1-CO resembles that associated with the structures located at the end of phase $I$ of the reaction between nitrone $\mathbf{1 b}$ and ketene 4b, emphasising its earlier character; (ii) as expected, at IN-CO, while the formation of the O1-C5 single bond is very advanced, the formation of the $\mathrm{C} 3-\mathrm{O} 4$ single bond has not yet begun; (iii) the bonding pattern of IN-CO resembles that of point $\mathbf{P 5}$ of the reaction between nitrone $\mathbf{1 b}$ and ketene $\mathbf{4 b}$. The main difference between IN-CO and P5 is the C3-O4 distance: 2.745 at IN-CO and $2.329 \AA$ at P5. The short C3-O4 distance at P5 justifies that this species is not a stationary point in the PES of the 32CA reaction between nitrone $\mathbf{1 b}$ and ketene $\mathbf{4 b}$; (iv) the bonding pattern of TS2-CO resembles that of TS-CO. The only difference is that TS2-CO is slightly more advanced than TS-CO; and (v) the GEDT at IN-CO and TS2-CO is larger than that at P5 and TS-CO as a consequence of the higher electrophilic character of ketene $4 \mathbf{c}$ than ketene $\mathbf{4 b}$. The higher polar character of the zw-type 32CA reaction between nitrone $\mathbf{1 b}$ and electrophilic ketene $\mathbf{4 c}$ permits the stabilisation of the zwitterionic intermediate, thus changing the molecular mechanism from a one-step mechanism to a two-step one, but the bonding changes in both 32CA reactions are essentially the same. This similar bonding pattern along the two 32CA reactions makes it possible to establish the non-concerted nature of the two-stage one-step mechanism. $^{49}$

\section{Conclusions}

A comprehensive MEDT study of the reaction between nitrones and ketenes has been carried out using DFT methods at the MPWB1K/6-311G(d,p) computational level. ELF analysis of nitrones confirmed their electronic structure as TACs participating in $z w$-type 32CA reactions although NPA clearly shows that the common representation as 1,2-zwitterions is incorrect. The analysis of CDFT reactivity indices of nitrones and ketenes correctly predicts the experimentally observed complete $\mathrm{C}=\mathrm{O}$ regio- and chemoselectivities. A detailed analysis of the PES corresponding to the reaction between nitrones and nonelectrophilically activated ketenes indicates that the reaction follows a two-stage one-step mechanism in which the formation of the second bond takes place once the first one is almost completely formed. No significant changes are observed by the inclusion of solvent effects. Analysis of the thermodynamic data indicates that while the initial 32CA reaction of the nitrone towards the ketene $\mathrm{C}-\mathrm{O}$ double bond is kinetically regio- and chemoselectively controlled, the products resulting from the addition of the ketene $\mathrm{C}-\mathrm{C}$ double bond can be obtained under thermal equilibrium conditions, in clear agreement with the experimental outcomes.

A complete BET study confirms the non-concerted nature of the reaction identifying the mechanism as a [2n,2n] process, i.e. only two non-bonding electrons of the oxygen lone pairs of the nitrone and two non-bonding electrons of the oxygen lone pairs of the ketene are mainly involved in the formation of the two C-O single bonds. Finally, an ELF topological analysis of the electron density distribution of the stationary points involved in the most favourable reactive channel associated with the 32CA reaction involving electrophilic ketenes predicts a switch of mechanism from two-stage one-step to two-step. Despite the change of mechanism, the bonding pattern is the same for the two reactions, thus the present computational study confirms the non-concerted nature of the cycloaddition between nitrones and ketenes.

\section{Acknowledgements}

This research was supported by the Spanish MINECO (FEDER CTQ2016-78669-P and CTQ2016-76155-R), and the Government of Aragón (Grupos Consolidados, E.10). M. R.-G. thanks MINECO for a pre-doctoral contract co-financed by the European Social Fund (BES-2014-068258). The authors thankfully acknowledge the resources from the supercomputers "Memento" and "Cierzo", technical expertise and assistance provided by BIFI-ZCAM (Universidad de Zaragoza, Spain).

\section{References}

1 L. Irvin, Chem. Rev., 1938, 23, 193-285.

2 P. N. Confalone and E. M. Huie, Org. React., 1988, 36, 1-174.

3 J. N. Martin and R. C. F. Jones, in Synthetic Applications of 1,3-Dipolar Cycloaddition Chemistry toward Heterocycles and Natural Products, ed. A. Padwa and W. H. Pearson, Wiley, Chichester, United Kingdom, 2002, vol. 59, pp. 1-81.

4 (a) P. Merino, in Science of Synthesis, ed. D. Bellus and A. Padwa, George Thieme, Stuttgart, 2004, vol. 27, pp. 511-580; (b) P. Merino, in Science of Synthesis, ed. E. Schaumann, George Thieme, Stuttgart, 2011, vol. 2010/4, pp. 325-403.

5 (a) S. Kanemasa, Synlett, 2002, 1371-1387; (b) S. Kanemasa, in Synthetic Applications of 1,3-Dipolar Cycloaddition Chemistry toward Heterocycles and Natural Products, ed. A. Padwa and W. H. Pearson, Wiley, Chichester, United Kingdom, 2002, vol. 59, pp. 755-815; (c) D. A. Evans, F. Kleinbeck and M. Rüping, in Asymmetric Synthesis - 
The Essentials, ed. M. Christmann and S. Bräse, Wiley-VCH, Weinheim, 2006, pp. 72-77.

6 K. Rück-Braun, T. H. E. Freysoldt and F. Wierschem, Chem. Soc. Rev., 2005, 34, 507-516.

7 (a) J. Revuelta, S. Cicchi, A. Goti and A. Brandi, Synthesis, 2007, 485-504; (b) A. Brandi, F. Cardona, S. Cicchi, F. M. Cordero and A. Goti, Chem. - Eur. J., 2009, 15, 78087821; (c) M. Frederickson, Tetrahedron, 1997, 53, 403-425; (d) K. V. Gothelf, in Cycloaddition Reactions in Organic Synthesis, ed. S. Kobayashi and K. A. Jorgensen, Wiley-VCH, Inc., New York, 2002, pp. 211-247.

8 (a) J. Malinina, T. Q. Tran, A. V. Stepakov, V. V. Gurzhiy, G. L. Starova, R. R. Kostikov and A. P. Molchanov, Tetrahedron Lett., 2014, 55, 3663-3666; (b) T. Kawai, K.-H. Kodama, T. Ooi and T. Kusumi, Tetrahedron Lett., 2004, 45, 4097-4099; (c) A. Padwa, D. N. Kline, K. F. Koehler, M. Matzinger and M. K. Venkatramanan, J. Org. Chem., 1987, 52, 3909-3917.

9 (a) D.-L. Mo, W. H. Pecak, M. Zhao, D. J. Wink and L. L. Anderson, Org. Lett., 2014, 16, 3696-3699; (b) J. Holt and A. Fiksdahl, J. Heterocycl. Chem., 2007, 44, 375379.

10 (a) N. Celebi-Oelcuem, Y.-h. Lam, E. Richmond, K. B. Ling, A. D. Smith and K. N. Houk, Angew. Chem., Int. Ed., 2011, 50, 11478-11482; (b) E. Richmond, N. Duguet, A. M. Z. Slawin, T. Lebl and A. D. Smith, Org. Lett., 2012, 14, 2762-2765; (c) A. R. Evans, M. Hafiz and G. A. Taylor, J. Chem. Soc., Perkin Trans. 1, 1984, 1241-1245.

11 K. Kavitha and P. Venuvanalingam, J. Chem. Soc., Perkin Trans. 2, 2002, 2130-2139.

12 A. Darù, D. Roca-López, T. Tejero and P. Merino, J. Org. Chem., 2016, 81, 673-680.

13 E. Richmond, K. B. Ling, N. Duguet, L. B. Manton, N. Çelebi-Ölçüm, Y.-H. Lam, S. Alsancak, A. M. Z. Slawin, K. N. Houk and A. D. Smith, Org. Biomol. Chem., 2015, 13, 1807-1817.

14 P. Hohenberg and W. Kohn, Phys. Rev., 1964, 136, B864B871.

15 L. R. Domingo, Molecules, 2016, 21, 1319.

16 L. R. Domingo and S. R. Emamian, Tetrahedron, 2014, 70, 1267-1273.

17 L. R. Domingo, M. Ríos-Gutiérrez and P. Pérez, Tetrahedron, 2016, 72, 1524-1532.

18 L. R. Domingo, M. J. Aurell and P. Pérez, Tetrahedron, 2014, 70, 4519-4525.

19 X. Krokidis, S. Noury and B. Silvi, J. Phys. Chem. A, 1997, 101, 7277-7282.

20 Y. Zhao and D. G. Truhlar, J. Phys. Chem. A, 2004, 108, 6908-6918.

21 W. J. Hehre, L. Radom, P. v. R. Schleyer and J. A. Pople, Ab initio Molecular Orbital Theory, Wiley, New York, 1986.

22 (a) H. B. Schlegel, J. Comput. Chem., 1982, 3, 214-218; (b) Modern Electronic Structure Theory, ed. H. B. Schlegel and D. R. Yarkony, World Scientific Publishing, Singapore, 1994.

23 K. Fukui, J. Phys. Chem., 1970, 74, 4161-4163.
24 (a) C. González and H. B. Schlegel, J. Phys. Chem., 1990, 94, 5523-5525; (b) C. González and H. B. Schlegel, J. Chem. Phys., 1991, 95, 5853-5860.

25 (a) J. Tomasi and M. Persico, Chem. Rev., 1994, 94, 20272094; (b) B. Y. Simkin and I. Sheikhet, Quantum Chemical and Statistical Theory of Solutions-Computational Approach, Ellis Horwood, London, 1995.

26 (a) E. Cances, B. Mennucci and J. Tomasi, J. Chem. Phys., 1997, 107, 3032-3041; (b) M. Cossi, V. Barone, R. Cammi and J. Tomasi, Chem. Phys. Lett., 1996, 255, 327-335; (c) V. Barone, M. Cossi and J. Tomasi, J. Comput. Chem., 1998, 19, 404-417.

27 (a) A. E. Reed, R. B. Weinstock and F. Weinhold, J. Chem. Phys., 1985, 83, 735-746; (b) A. E. Reed, L. A. Curtiss and F. Weinhold, Chem. Rev., 1988, 88, 899-926.

28 A. D. Becke and K. E. Edgecombe, J. Chem. Phys., 1990, 92, 5397-5403.

29 M. J. Frisch, et al., Gaussian 09, Revision A.02, Gaussian Inc., Wallingford CT, 2009.

30 S. Noury, X. Krokidis, F. Fuster and B. Silvi, Comput. Chem., 1999, 23, 597-604.

31 (a) R. G. Parr and W. Yang, Annu. Rev. Phys. Chem., 1995, 46, 701-728; (b) H. Chermette, J. Comput. Chem., 1999, 20, 129-154; (c) F. De Proft and P. Geerlings, Chem. Rev., 2001, 101, 1451-1464; (d) P. Geerlings, F. De Proft and W. Langenaeker, Chem. Rev., 2003, 103, 1793-1873; (e) P. W. Ayers, J. S. M. Anderson and L. J. Bartolotti, Int. J. Quantum Chem., 2005, 101, 520-534; (f) J. L. Gázquez, J. Mex. Chem. Soc., 2008, 52, 3-10; (g) R. F. Nalewajski, J. Korchowiec and A. Michalak, Density Functional Theory IV, Topics in Current Chemistry, Springer, Berlin, Heidelberg, 1996, vol. 183, p. 25; (h) P. Geerlings, S. Fias, Z. Boisdenghien and F. De Proft, Chem. Soc. Rev., 2014, 43, 4989-5008.

32 R. G. Parr, L. von Szentpaly and S. Liu, J. Am. Chem. Soc., 1999, 121, 1922-1924.

33 (a) R. G. Parr and R. G. Pearson, J. Am. Chem. Soc., 1983, 105, 7512-7516; (b) R. G. Parr and W. Yang, Density Functional Theory of Atoms and Molecules, Oxford University Press, New York, 1989.

34 (a) L. R. Domingo, E. Chamorro and P. Pérez, J. Org. Chem., 2008, 73, 4615-4624; (b) L. R. Domingo and P. Pérez, Org. Biomol. Chem., 2011, 9, 7168-7175.

35 W. Kohn and L. J. Sham, Phys. Rev., 1965, 140, 11331138.

36 L. R. Domingo, P. Pérez and J. A. Sáez, RSC Adv., 2013, 3, 1486-1494.

37 L. R. Domingo, E. Chamorro and P. Pérez, Lett. Org. Chem., 2010, 7, 432-439.

38 L. R. Domingo, M. Ríos-Gutérrez and P. Pérez, Molecules, 2016, 21, 748.

39 L. R. Domingo, RSC Adv., 2014, 4, 32415-32428.

40 L. R. Domingo, M. J. Aurell, P. Pérez and R. Contreras, Tetrahedron, 2002, 58, 4417-4423.

41 P. Jaramillo, L. R. Domingo, E. Chamorro and P. Pérez, J. Mol. Struct. (THEOCHEM), 2008, 865, 68-72. 
42 (a) R. Pratt, D. P. Stokes and G. A. Taylor, J. Chem. Soc., Perkin Trans. 1, 1975, 498-503; (b) A. F. Gettins, D. P. Stokes and G. A. Taylor, J. Chem. Soc., Perkin Trans. 1, 1977, 18491855; (c) M. Hafiz and G. A. Taylor, J. Chem. Soc., Perkin Trans. 1, 1980, 1700-1705; (d) A. R. Evans, M. Hafiz and G. A. Taylor, J. Chem. Soc., Perkin Trans. 1, 1984, 1241-1245; (e) C. P. Falshaw, M. Hafiz and G. A. Taylor, J. Chem. Soc., Perkin Trans. 1, 1985, 1837-1843.

43 M. Ríos-Gutiérrez, P. Pérez and L. R. Domingo, RSC Adv., 2015, 5, 58464-58477.

44 L. R. Domingo and J. A. Sáez, Org. Biomol. Chem., 2009, 7, 3576-3583.

45 (a) S. Berski, J. Andrés, B. Silvi and L. R. Domingo, J. Phys. Chem. A, 2003, 107, 6014-6024; (b) V. Polo, J. Andrés, S. Berski, L. R. Domingo and B. Silvi, J. Phys. Chem. A, 2008, 112, 7128-7136; (c) J. Andrés, P. Gonzáez-Navarrete and V. Safont, Int. J. Quantum Chem., 2014, 114, 1239-1252.

46 (a) R. Thom, Structural Stability and Morphogenesis: An Outline of a General Theory of Models, Inc., Reading,
MA, 1976; (b) A. E. R. Woodcock and T. Poston, A Geometrical Study of Elementary Catastrophes, Spinger-Verlag, Berlin, 1974; (c) R. Gilmore, Catastrophe Theory for Scientists and Engineers, Dover, New York, 1981.

47 (a) V. Polo, J. Andrés, R. Castillo, S. Berski and B. Silvi, Chem. - Eur. J., 2004, 10, 5165-5172; (b) J. C. Santos, J. Andrés, A. Aizman, P. Fuentealba and V. Polo, J. Phys. Chem. A, 2005, 109, 3687-3693; (c) S. Berski, J. Andrés, B. Silvi and L. R. Domingo, J. Phys. Chem. A, 2006, 110, 13939-13947; (d) V. Polo and J. Andrés, J. Chem. Theory Comput., 2007, 3, 816-823; (e) S. Berski and Z. Ciunik, Mol. Phys., 2015, 113, 765-781.

48 L. R. Domingo, M. Ríos-Gutiérrez and J. A. Sáez, RSC Adv., 2015, 5, 37119-37129.

49 L. R. Domingo, J. A. Saéz, R. J. Zaragozá and M. Arnó, J. Org. Chem., 2008, 73, 8791-8799.

50 M. Ríos-Gutiérrez, P. Pérez and L. R. Domingo, RSC Adv., 2015, 5, 84797-84809. 